\title{
A new method for tutorial gap identification towards students modeling
}

\author{
Atanu Das ${ }^{1 *}$, Kaustuv Deb ${ }^{2}$, Sonali Bajerjee ${ }^{2}$, Rajib Bag ${ }^{2}$ \\ ${ }^{1}$ Netaji Subhash Engineering College, Kolkata, India \\ ${ }^{2}$ Supreme Knowledge Foundation Group of Institutions, Mankundu, WB, India \\ Email: atanudas75@yahoo.co.in
}

\begin{abstract}
Students modeling is an integral part of any form of education and this becomes more challenging with the advent of new tools of ICT especially Intelligent Tutoring Systems (ITS). Educators must have to take help of such tools to identify the curriculum gaps towards Outcome Based Education (OBE). One of the ways to reduce such gaps is to identify the personalized requirements of tutorials for learners after going through some topics divided into subtopics. This paper proposes a technique to identify the personalized tutorial gaps by analyzing the responses provided by students against MCQ type questions. The proposed method has been implemented within a web based environment. Prototype of the tool having integrated with the proposed method shows that the students can identify their tutorial requirement without the help of human tutor and hence discovering the student's understanding.
\end{abstract}

Keywords: ICT, OBE, Tutorial, Gap, Students Modeling.

\section{INTRODUCTION}

Educational world has been experiencing a paradigm shift from teacher centric education to outcome based education (OBE) [1-3] during last two decades. OBE has become accreditation requirements through out the world. OBE ensures cyclical processes which gurantes continuous improvement towards excellence. These cyclical processes involve implementing different mechanism for efficient student modeling. Students performances can not be enhanced unless such modeling is not assured at least at some desired level.

A student model is a representation of student understanding of a topic being taught. The model constructed by human tutors become more accurate with the experiences of the tutor. Such model construction is a difficult task and varies with teaching domains and teaching experiences. Often Intelligent Tutoring Systems (ITS) [5] have been used since the advent of using ICT tools for education for standardization of students modeling. Such models are used as personalized cognitive tool within the Intelligent Learning Environment (ILE).

There are several knowledge components within the representation of the students model. According to curriculum requirements, some components are required to be achieved by tutorials. But requirements of tutorials is not defined a priori in the curriculum most of the times and decided by human tutor as per his own experiences not according to learner's personalized model requirements.

This work advocates the use of automated ICT tools, if not ITS, for identifying personalized tutorials requirement gaps after going through some set of topics (defined in the curriculum) or subtopics (subdivisions of topic). This identification could be achieved by analysing the responses of the students on a simple web based well designed MCQ test. There are two challenges in these endeavour. First is to design the MCQ test questions having one-to-many relationship maping with the subtopic level content. Second step is to analyse the responses corresponding to the questions to identify knowledge gap (also treated as curriculam gap) which could be fullfilled through the tutorial works specially. The last challenge has been focused in this work mostly.

\section{RELATED WORKS}

With the advent of OBE [1-3], education systems turning to exhibit more professionalism as expected in the developing economies. Outcome becomes the primary focus in these systems and accreditation requirement enforces to measure the same from a good number of parameters [1] among which one crucial is initiatives taken to bridge the curriculum gap besides competency assessments [6-9] of students after curriculum execution. One well known curriculum components are tutorial often ignored by human tutors because of shortage in time mostly. But even if time is strictly allocated for the same, inexperience teachers could not identify or wrongly identify the topics or subtopics on which tutorials classes need to be conducted at least for majority of students if not for all. Even though the teacher is having huge experience, he needs to analyse intelligently 
each individual student before moving in to tutorial classes. To reduce the overload of human tutors, ICT based ITS [5] have been evolved which often took part in student modelling using knowledge based machine learning techniques.

It has been observed that construction of student model is a time-consuming task. Normally this is based on expert human inputs [14]. Structured interviews are conducted and the inputs are lucidly analysed for the same. Crucial instructional implications show that human engineering towards these models disregard the peculiarities between content and learning [11-12]. Learning Factor Analysis (LFA) [13] is another technique where automated search techniques are implemented for identification of knowledge components of the students' model. However, LFA conducts search processes in the closed periphery of human supplied factors. Nevertheless, these methods are somehow dependent on machines learning techniques [10] including complex mechanism.

To reduce these complexities, we propose a technique based on the analysis of student's responses on MCQ questions since the scope of this work is to model the student's tutorial requirements. The proposed scheme is somehow adhoc and expressive but includes procedural approaches.

\section{PROPOSED METHOD}

The curriculum gap identification required for $\mathrm{OBE}$ assessment has been considered here using identification of required tutorials as one of the crucial curriculum components. Educational delivery of the proposed system has been planned considering to the following processes.

1. Dividing the syllabus of a course into several topics as per lecture/delivery plan.

2. Delivery of contents on subtopics (unit of content delivery) of a topic.

3. Generation of MCQ questions set comprising questions having one-to-many relationship with the subtopics.

4. Conducting MCQ test for the students and collecting the question wise responses of the students.

5. Processing the student's responses to identify subtopics wise gap to be filled by tutorials based on some predefined threshold.

The scheme of the processing in the stage 5 is depicted below:

We consider a course with $\mathrm{m}$ modules. Now each module $\mathrm{M}_{\mathrm{i}}$, $(1 \leq \mathrm{i} \leq \mathrm{m})$ is divided into $\mathrm{n}$ number of topics. This method is going to operate on a particular topic Topi $\mathrm{i}_{\mathrm{ij}},(1 \leq \mathrm{j}$ $\leq \mathrm{n})$. Each Topi $\mathrm{i}_{\mathrm{ij}}$ is divided into $\mathrm{p}$ subtopics. A subtopic is denoted by Sutopi $i_{i j k},(1 \leq k \leq p)$.

After completion of the delivery of contents on each subtopics of the topic Topi $\mathrm{i}_{\mathrm{ij}}$ to a student, the student has to give test on question set $\mathrm{Q}_{\mathrm{ij}}$ which is set on the subtopics of $\mathrm{Topi}_{\mathrm{ij}}$. $\mathrm{Q}_{\mathrm{ij}}$ comprises of $\mathrm{v}$ number of questions. Each question $\mathrm{Q}_{\mathrm{ijz}}, 1 \leq \mathrm{z} \leq \mathrm{v}$, in $\mathrm{Q}_{\mathrm{ij}}$ can be set on one or more subtopics of $\mathrm{Topi}_{\mathrm{ij}}$.

We use a $\mathrm{v} \times \mathrm{p}$ matrix MQSutopi showing the mapping between $v$ questions in $\mathrm{Q}_{\mathrm{ij}}$ and $\mathrm{p}$ subtopics.

MQSutopi [r] [s] = 1, if $\mathrm{Q}_{\mathrm{ijr}}$ is set on Sutopi $\mathrm{i}_{\mathrm{ijs}}$,

MQSutopi $[\mathrm{r}][\mathrm{s}]=0$, otherwise, for $1 \leq \mathrm{r} \leq \mathrm{v}$ and $1 \leq \mathrm{s} \leq \mathrm{p}$.
MESutopi [r] [s] = 1, if MQSutopi[r][s]=1 and the student has given correct answer to question $\mathrm{Q}_{\mathrm{ijr}}$, set on subtopic Sutopi $\mathrm{i}_{\mathrm{ijs}}$.

MESutopi $[\mathrm{r}][\mathrm{s}]=0$, otherwise, for $1 \leq \mathrm{r} \leq \mathrm{v}$ and $1 \leq \mathrm{s} \leq \mathrm{p}$.

CASutopi $[\mathrm{t}]=$ Total number of 1 's present in the $\mathrm{t}^{\text {th }}$ column of matrix MESutopi.

We maintain an array CASutopi (decision variable) of size $\mathrm{p}$ such that for $1 \leq \mathrm{t} \leq \mathrm{p}$. It may be noted that total number of 1 's present in the $t^{\text {th }}$ column of matrix MESutopi signifies how many questions on subtopic Sutopi $i_{i j b}$ are correctly answered by a student. If the value in CASutopi[t] is less than threshold $\mathrm{Th}_{\mathrm{ijt}}$, then we find a tutorial gap in subtopic Sutopi $_{i j t}$ for the student and assign tutorials to the student on subtopic Sutopi ijt.

The threshold plays very important role in this method. Threshold normally decided according to two aspects: (1) academic level (e.g. age, class etc.), (2) academic standard (e.g. rank of the institutes in global or national scenarios). If same content and test questions are used for this purpose, the threshold could vary with respect to academic levels. For example, school educators will use low threshold compared to college level institutes or UG level will set low threshold compared to PG courses

On the other hand, if the same system is used in different institutes, they should have the liberty to set the threshold according the quality of education they are expecting. OBE also advocates continuously improving the quality of the outcome and hence they need to increase the threshold gradually according to educational objectives, mission and vision of the institutes.

\section{IMPLEMENTATION}

The proposed technique is implemented using a web based system developed using PHP-MySQL technology using WAMP server at the back and functioning like an small ITS. Such technology has been chosen because of their simplistic nature and easiness from developer's perspective. Since the focus is to implement the tutorial gap identification scheme, the content delivery parts of the proposed system is not discussed and presented here. Following figure 1 presents the simple interface of implementation of test students need to undergo inside the system as an evidence of conducting test and collecting responses using an automated system.

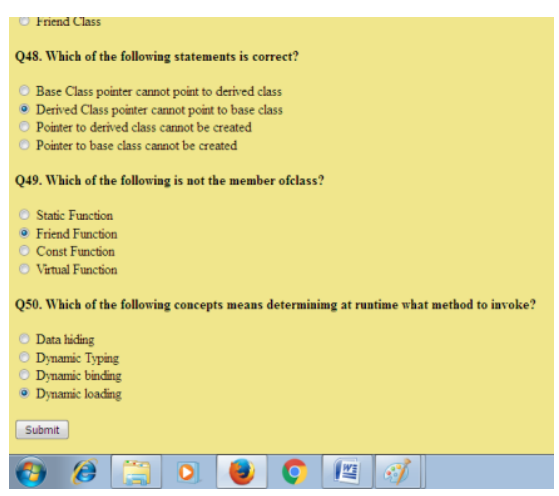

Figure 1. Evidence of conducting MCQ Test

The following figure 2 presents the interface of subtopic wise analysis report according to the proposed scheme. 
The following figure 3 presents the interface of the proposed system proving discovered instructions to the students about their tutorial requirements so that they can go through the required tutorials and offering the educational outcome as expected from the system as per regulatory framework.

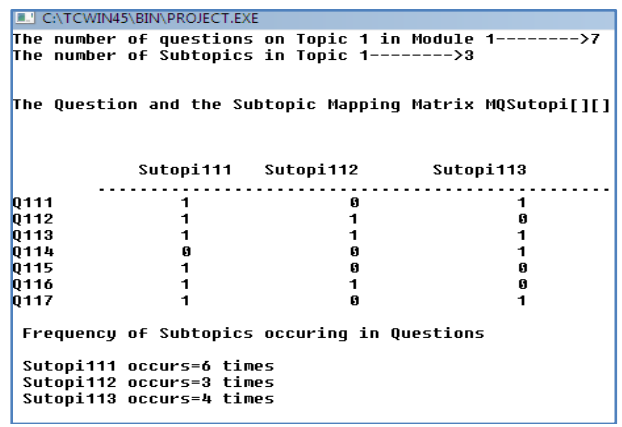

Figure 2. Subtopic wise analysis of responses to MCQ questions

\begin{tabular}{|c|c|c|}
\hline \multirow{2}{*}{\multicolumn{3}{|c|}{ 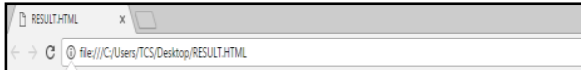 }} \\
\hline & & \\
\hline \multicolumn{3}{|c|}{ 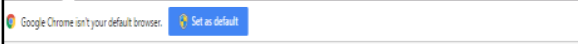 } \\
\hline SUPTOPIC & MARKS OBTAN & RESULT \\
\hline SUBTOPIC1 & $6667 \%$ & PASSED \\
\hline SUBTOPIC2 & $50 \%$ & FAlLED(TUTORIILL PRONDED) \\
\hline SUBtopic3 & $50 \%$ & FAlLED(UUORRILL PROVDED) \\
\hline SUBTOPICA & $100 \%$ & PASSED \\
\hline SUBTOPIC5 & $66.67 \%$ & PASSED \\
\hline SUBTOPIC6 & $50 \%$ & FAlLED(UTORRILL PRONDED) \\
\hline
\end{tabular}

Figure 3. Recommendation report based on analysis using proposed method

The prototype of the proposed system (integrated with the identification scheme), can be improved to work more fruitfully having many features of ITS.

\section{RESULTS AND DISCUSSIONS}

The developed web based tool was examined through some testing procedure. Though the proposed technique can be used for tutorial gap identification irrespective of any level of education having computer literate target students, the testing was focused on $2^{\text {nd }}$ and $3^{\text {rd }}$ year Computer Science and Engineering students. First experiment conducted with the 50 students of second year Computer Science and Engineering divided into two groups on the course computer organization. It has been observed that the developed method could identify one or more tutorial gap predefined while designing the content and agreed on the MCQ questions for $75 \%$ cases. Second experiment conducted on the same set up on third year student on the course operating system but result shows that in around $80 \%$ cases predefined gap has been identified. Result of identification observed to be poor a little for $2^{\text {nd }}$ year due to heterogeneous background on account of lateral entry students' consideration perhaps.

So, we can say that the proposed scheme found efficient at least for engineering education. Further experiment on this regard is yet to be conducted for others educational scenarios. It is also expected that the results may further be improved if better care is taken while design the instructional materials and questions set. On this view, research may further be extended towards standardization of personalized content and questions which was beyond the scope of this venture.

\section{CONCLUSIONS}

This paper contributes to the literature by proposing a new technique for curriculum gap identification through tutorial recommendation. This paper also advocates the use of automated ICT based tools for such gap identification. This ICT based tools will be able to overcome the limitations of human tutors having diversified experience and teaching styles. Personalized students' models could be presented having deficiencies pointed there in with the help of the use of ICT tools integrated with the proposed technique. Extended version of this proposed technique can be integrated within an ITS so that learning experience could be made better and convert it as ILE. Not only ITS implementation, but conceptualization of the method can improve the teaching performance and hence students' performance with respect to OBE. More use of machine learning and pattern recognition techniques can uplift the work to a level where professional success of educators will not be far away.

\section{REFERENCES}

[1] Handbook of training evaluation and measurement methods. (2016). Routledge, Oxon, UK.

[2] Spady W. (1994). Choosing outcomes of significance, Educational Leadership, Vol. 5, No. 1, pp. 18-23.

[3] Spady W., Marshall K. (1994). Beyond traditional outcome-based education, Educational Leadership, Vol. 49, No. 2, pp. 67-72.

[4] Zaman W., Das A., Basu P.N. (2007). A survey on computer based training----an Indian perspective, Proc. of Int. Conf. on Emerging Trends in Electrical Engineering, Dept. of EE, Jadavpur University at Science City, Kolkata, India, pp. 492-497.

[5] Bag R., Das A. (2010). Developing an intelligent tutoring system following Bayesian approach, Int. J. of Advanced Engineering \& Applications, Vol. 2, pp. 114-119.

[6] Mitra M., Das A. (2015). A fuzzy logic approach to assess web learner's joint skills, Int. J. of Modern Education and Computer Science, Vol. 9, pp. 14-21. DOI: $\underline{10.5815 / \mathrm{ijmecs} .09 .02}$

[7] Bose D., Das A. (2015). Using fuzzy trapezoidal rule for web learner's competence assessment, Int. J. of Electronics and Communication Technology, Vol. 6, No. 1, pp. 169-173.

[8] Banerjee S., Bag R., Das A. (2016). Design and development of a web based teaching performance assessment tool with student feedback and fuzzy logic, 3rd Int. Conf. on Foundations and Frontiers in Computer, Communication and Electrical Engineering (C2E2-2016), 15th-16th January, 2016 at SKFGI, Mankundu, Hooghly, WB, India, pp. 475-479, DOI: 10.1201/b20012-93

[9] Mitra M., Das A. (2013). Applying a fuzzy technique for web-based learner's performance evaluation, Proc. of National Conf. on Control, Communication \& Device 
Electronics (N3CD-2013), JIS Engineering College, Kalyani, WB, India, pp. 125-131.

[10] Sison R., Shimura M. (1998). Student modelling and machine learning, Int. J. of Artificial Intelligence in Education, Vol. 9, pp. 128-158.

[11] Koedinger K.R., Nathan M.J. (2004). The real story behind story problems: effects of representations on quantitative reasoning, The Journal of Learning Sciences, Vol. 13, No. 2, pp. 129-164.

[12] Koedinger K.R., McLaughlin E.A. (2010). Seeing language learning inside the math: cognitive analysis yields transfer, In Proc. of the 32nd Annual Conf. of the Cognitive Science Society, Austin, TX, pp. 471-476.

[13] Cen H., Koedinger K., Junker B. (2006). Learning factors analysis-a general method for cognitive model evaluation and improvement, In Proc. of the 8th Int. Conf. on Intelligent Tutoring Systems, pp. 164-175.

[14] Li N., Cohen W., Koedinger K.R., Matsuda N. (2011). A machine learning approach for automatic student model discovery, In Educational Data Mining. 